\title{
Epidemiological trend in the distribution of cancer in Kashmir Valley
}

\author{
G M Dhar, G N Shah, B Naheed, Hafiza
}

\begin{abstract}
Study objective-To study the distribution of cancers, with particular emphasis on oesophageal cancer.

Design-Patient records for 1986-88 in the Department of Oncology, SK Institute of Medical Sciences, were searched to identify cases and types of cancer.

Setting-The Valley of Kashmir, India.

Subjects-Patients with cancer resident in the valley.

Main results-The seven most common types of cancer in men were those of the oesophagus, lungs, stomach, skin, upper respiratory tract, and urinary tract. In women the most common types of cancer were those affecting the oesophagus, breast, cervix, stomach, skin, colon/rectum, and lungs. Cancer of the oesophagus was the most frequent type in both sexes, accounting for $42.9 \%$ of all types of cancer in the valley. This distribution of cancer types is strikingly different from that in the rest of India where oropharyngeal cancer is the most common form. Again, contrary to the trend in India as a whole, cervical cancer is not a leading type of cancer in the valley and is less frequent even than cancer of the breast in the women. Conclusions-The preponderance of oesophageal cancer was attributable to the local practice of drinking boiling hot salt tea. Universal male circumcision in the majority community in the valley was considered to be partly responsible for low cervical cancer frequency.
\end{abstract}

f Epidemiol Community Health 1993; 47: 290-292

Altogether 4.3 million deaths from cancer occur world wide annually, of which 2.3 million are in the developing countries. ${ }^{1}$ Of all the cancer sites studied so far, oesophageal cancer shows the widest geographical variation. While in most areas of Europe and North America its incidence is below 6/100 000 men and 3/100 000 women, in some regions in Iran and China the incidence is as high as 100/100 100 for both sexes. Environmental factors are considered to be responsible for the geographical variation, and cigarette smoking and alcohol consumption have been reported to have a causal relationship with oesophageal cancer. $^{2,3}$ Nevertheless, oesophageal cancer remains a disease of a multifactorial aetiology and some as yet unexplored factors may play a part in the wide regional variation.

Within the Indian subcontinent, the Valley of Kashmir presents a strikingly different picture of cancer distribution. While oropharyngeal cancer is the most common type in India, oesophageal cancer is the most predominant form in Kashmir. Again, while cervical cancer has a higher incidence than breast cancer in India as a whole, the situation is the reverse in Kashmir. ${ }^{4}$

This study, which attempts to examine the epidemiological distribution of common cancer types in Kashmir, is based on the records of cancer patients treated in the Radiation Oncology Department of the SK Institute of Medical Sciences, Srinagar, which is the leading medical centre in the valley and draws a substantial proportion of cancer patients from all over Kashmir for treatment.

\section{Methods}

The patients' records were screened for information on the nature and distribution of all forms of cancer reported to the department between January 1986 and December 1988 (that is, before the social disturbances in the valley). Records of patients from outside the valley of Kashmir were excluded from the study. The mean annual frequencies of all cancer types were worked out by district and tabulated by sex. The main forms of cancer were identified separately for men and women as well as collectively. The predominance of oesophageal cancer was highlighted. An attempt was made to interpret the distribution of cancer on epidemiological grounds. The sex differential was subjected to the $\chi^{2}$ test based on actual frequencies.

\section{Results}

The nine main types of cancer (table I), in order of their frequency, are those of the oesophagus, lung, breast, stomach, skin, colon/rectum, upper respiratory tract, and urinary tract. With a mean annual frequency of $187 \cdot 66$, oesophageal cancer has the highest morbidity. While in men lung cancer $(20 \cdot 62 \%)$ and stomach cancer $(10 \cdot 38 \%)$ are the next two most frequent forms, in women breast cancer $(22.42 \%)$ and cervical cancer (11.92\%) follow oesophageal cancer. In cancer types common to both sexes, the proportion in the men exceeds that in the women; the sex differential in cancer of the oesophagus and lung is statistically highly significant.

With regard to distribution by district, the mean annual frequency of oesophageal cancer (table II) shows that it varies in proportion to the population size and is therefore higher in the three populous districts of Srinagar, Baramulla, and Anantnag. Baramulla shows the highest frequency of oesophageal cancer in men $(23.89 \%)$, and 
Table I Mean annual frequency of the nine most common types of cancer in relation to gender

\begin{tabular}{|c|c|c|c|c|}
\hline Rank & $\begin{array}{l}\text { Cancer } \\
\text { type }\end{array}$ & $\begin{array}{l}\text { Men } \\
\text { Mean annual } \\
\text { frequency (\%) }\end{array}$ & $\begin{array}{l}\text { Women } \\
\text { Mean annual } \\
\text { frequency (\%) }\end{array}$ & $\begin{array}{l}\text { Total } \\
\text { Mean Annual } \\
\text { frequency (\%) }\end{array}$ \\
\hline 1 & Oesophagus & $113.00(49.57)$ & $74 \cdot 65(45 \cdot 25)$ & $187.66(47 \cdot 75)^{\star}$ \\
\hline 2 & Lung & $47.00(20.62)$ & $4 \cdot 00(2 \cdot 42)$ & $51.00(12.98)^{\star}$ \\
\hline 3 & Breast & - & $37.00(22.42)$ & $37.00(9.42)$ \\
\hline 4 & Stomach & $23.66(10.38)$ & $10 \cdot 34(6 \cdot 27)$ & $34.00(8.65)$ \\
\hline 5 & Skin & $15.66(6.87)$ & $7.67(4.65)$ & $23.33(5.94)$ \\
\hline 6 & Cervix & - & $19.66(11.92)$ & $19.66(5.00)$ \\
\hline 7 & Colon/rectum & $12.33(5 \cdot 40)$ & $6.33(3.84)$ & $18.66(4.75)$ \\
\hline 8 & Upper respiratory & & & \\
\hline \multirow{3}{*}{9} & tract & $8.66(3.80)$ & $3.34(2.02)$ & $12 \cdot 00(3.05)$ \\
\hline & Urinary tract & $7.66(3.36)$ & $2.00(1.21)$ & $9.66(2.46)$ \\
\hline & Total & $227.97(100 \cdot 00)$ & $165.00(100 \cdot 00)$ & $392.97(100.00)$ \\
\hline
\end{tabular}

${ }^{\star} \mathrm{p}<0 \cdot 0001$ (highly significant) temperature falls to subzero levels. The salt tea, indigenous to the valley, is prepared traditionally in a specially designed copper vessel called a 'samawar'. The samawar consists of a central smoke stack with a perforated base (fed with live charcoal) mounted on a stand and a surrounding jacket for boiling the salt tea infusion. The tea is customarily served at boiling point and is consumed with or without snacks.

Lung cancer ranks next to oesophageal cancer in the valley. Its causal association with smoking has been substantiated by innumerable studies, some of which have also established a doseresponse relationship, in terms of the number of cigarettes smoked per day and the risk of developing lung cancer. ${ }^{5-8}$ While tobacco consumption is falling in the industrial world by about $1 \%$ annually, it is rising by twice that rate in the developing countries largely because of the aggresive advertising and marketing campaigns launched by the tobacco companies, so that today China leads the world in tobacco consumption. Consequently, lung cancer, which used to be rare in developing countries, is fast emerging as a public health problem. ${ }^{9}$ Smoking is popular throughout India, where besides cigarettes, pipes and cigars, it takes various indigenous forms such as bidi, hookah, and chilam. In Kashmir, besides cigarette smoking, which is mainly practised in urban and semiurban localities, hookah smoking is the most popular form and is largely responsible for passive smoking of other family members, especially during winter months, when soot, smoke, and fumes from kitchens and various types of heating pollute the indoor air in ill ventilated and overcrowded dwellings. Smoking in the valley is a male pastime, the women do not generally smoke.

Sex differentials in the nature and distribution of various forms of cancer are attributable to anatomical, physiological, and behavioural differences. In respect of oesophageal cancer in Kashmir, however, these factors seem to melt under the overwhelming influence of environmental correlates to the extent that this cancer is the most common even in the women, in whom it exceeds by far the frequencies of breast and cervical cancers. This is an observation of epidemiological importance attributable to hot salt tea consumption by both sexes. The relatively higher prevalence of oesophageal cancer in the men may result from the additional influence of smoking. Another interesting observation is that the frequency of breast cancer exceeds that of cervical cancer in the women. The practice of universal circumcision, prevalent in the majority community of Kashmir, may be partly responsible for the reverse trend. While in developed countries, such as the USA, lung cancer is a leading cause of death in both sexes, it is mostly a disease of men in India, as is also shown in this study. The higner frequency of skin cancer in the men is perhaps caused by the greater exposure to the sun that they receive especially while farming. Women are well covered, even while working in the fields. On statistical grounds, however, out of the seven leading cancer types that affect both the sexes, the male predilection was found to be significant $(p<0.0001)$ in respect of oesophageal and lung cancers only. 
1 Osuntokun BO. The changing pattern of disease in developing countries. World Health Forum 1988; 6: 310-13. 2 Aurelio C, Jesus V, Fransisco B. Oesophageal cancer mortality: relationship with alcohol intake and cigarette smoking in Spain. 7 Epidemiol Community Health 1991; 45: 273-6.

3 Cesar GV, Nubia M, Nicholas ED, Lucio BB, Debora AP, Noris MB. Hot beverages and oesophageal cancer in southern Brazil. Int $\mathcal{f}$ Cancer 1987; 39: 710-16.

4 World Health Organisation. A decade of health development in SE Asia, 1968-1977. SEARO: New Delhi, 1978.

5 Ernest LW, Kiychiko M, Edward JB. The epidemiology of Ernest LW, Kiychiko M, Edward JB. The
Lung Cancer. $¥ A M A$ 1970; 213: 2221-7.
6 Wynder EL, Munskinski M. Tobacco and alcohol consumption in relation to the development of multiple primary cancer. Cancer 1977; 40: 1872-8.

7 Taylor J, Piper DW. The carcinogenic effect of cigarette smoke. The effect of cigarette smoke on human gastric mucosal cell in organ cultures. Cancer 1971; 39: 2520.

8 Arya SN, Kumar R, Snajay A. Hazards of smoking. F Indian Med Assoc 1991; 89: 98-100.

9 Stanely K, St Jernsward J. Readers forum. World Health Forum 1985; 6: 350.

10 Vishwanathan R, Sengupta R. Incidence and etiology of lung cancer in India. Indian $尹$ Chest Dis Allied Sci 1961; 3: 193. 